\title{
White Rice Consumption and CVD Risk Factors among Iranian Population
}

\author{
Hossein Khosravi-Boroujeni', Nizal Sarrafzadegan', Noushin Mohammadifard', Firouzeh \\ Sajjadi', Maryam Maghroun', Sedigheh Asgari', Mahmoud Rafieian-kopaei ${ }^{2}$, Leila Azadbakht ${ }^{3,4}$ \\ 'Isfahan Cardiovascular Research Center, Isfahan Cardiovascular Research Institute, Isfahan University of Medical Sciences, \\ Isfahan, Iran; ${ }^{2}$ Medical Plants Research Center, Shahrekord University of Medical Sciences, Shahrekord, Iran; ${ }^{3}$ Food Security \\ Research Center, Isfahan University of Medical Sciences, Isfahan, Iran; ${ }^{4}$ Department of Community Nutrition, School of \\ Nutrition and Food Science, Isfahan University of Medical Sciences, Isfahan, Iran
}

\begin{abstract}
Association between white rice intake and risk factors of cardiovascular diseases remained uncertain. Most of the previous published studies have been done in western countries with different lifestyles, and scant data are available from the Middle East region, including Iran. This cross-sectional study was conducted in the structure of Isfahan Healthy Heart Program (IHHP) to assess the association between white rice consumption and risk factors of cardiovascular diseases. In the present study, 3,006 men were included from three counties of Isfahan, Najafabad, and Arak by multistage cluster random-sampling method. Dietary intake was assessed with a 49-item food frequency questionnaire (FFQ). Laboratory assessment was done in a standardized central laboratory. Outcome variables were fasting blood glucose, serum lipid levels, and anthropometric variables. Socioeconomic and demographic data, physical activity, and body mass index (BMI) were considered covariates and were adjusted in analysis. In this study, Student's $t$-test, chi-square test, and logistic regression were used for statistical analyses. Means of BMI among those subjects who consumed white rice less than 7 times per week and people who consumed 7-14 times per week were almost similar-24.8 \pm 4.3 vs $24.5 \pm 4.7 \mathrm{~kg} / \mathrm{m}^{2}$. There was no significant association between white rice consumption and risk factors of cardiovascular diseases, such as fasting blood sugar and serum lipid profiles. Although whole grain consumption has undeniable effect on preventing cardiovascular disease risk, white rice consumption was not associated with cardiovascular risks among Iranian men in the present study. Further prospective studies with a semi-quantitative FFQ or dietary record questionnaire, representing type and portion-size of rice intake as well as cooking methods and other foods consumed with rice that affect glycaemic index (GI) of rice, are required to support our finding and to illustrate the probable mechanism.
\end{abstract}

Key words: Cardiovascular diseases; Diet; Risk factors; White rice; Iran

\section{INTRODUCTION}

Cardiovascular diseases (CVDs) are the major causes of early death among men and women in developed countries (1). Increased rate of this disease has been reported from the developing countries, recently (2). CVDs are the causes of about half of deaths (43\% in men and 55\% in women) in European countries (2). Mortality rates due to CVDs

Correspondence and reprint requests:

Dr. Leila Azadbakht

Department of Community Nutrition

School of Nutrition and Food Science

Isfahan University of Medical Sciences

PO Box 81745

Isfahan, Iran

Email: azadbakht@hlth.mui.ac.ir

Fax: +983116682509 differ with gender, age, ethnicity, socioeconomic status, and geographical region (1).

Iran, as a developing country in the Middle East, has adopted the western lifestyle both in nutritional and physical activity habits which led to a rise in the prevalence of CVDs (3). Over the last decade, CVDs have been considered the main causes of mortality in Iran (4), and the prevalence continues to rise (5). Generally, a combination of several risk factors could be considered the cause of CVDs. Smoking, obesity, high blood pressure, and cholesterol can be mentioned as the most important wellknown risk factors (6). In the development of obesity and cardiovascular diseases, dietary factors have an important role (7). In the prevention of CVDs, dietary approaches are 
more cost-effective, more suitable, and safer than medical approaches (8). Dietary recommendation could protect against cardiovascular disease $(1,9,10)$. Whole grains are major components of a healthy diet in the prevention of cardiovascular diseases (11). The defending effect of whole grain-containing foods may depend on the existence or interaction of some biologically-active factors, such as dietary fibre, magnesium, vitamin E, folate, and other components (12). During the refining process, outer layer of grain containing bran and germ is separated. So, white rice that only contains the endosperm (starch) is produced, which can have adverse effects on cardiovascular disease risks and glucose metabolism (13). Fibre, minerals, vitamins, phytoestrogens, and phenolic compounds are usually found in whole grains, which are protective against diabetes and CVDs but these may be removed during the refining and milling process (14). Quality and quantity of carbohydrate which we know as glycaemic index (GI) and glycaemic load (GL) have also important role in the development of chronic diseases, particularly CVDs and diabetes (15). Foods with higher GI, as in white rice, can cause a quick postprandial increase in insulin secretion and blood glucose level and have increased risk of diabetes and cardiovascular disease in western (16) and Asian populations (17). Recently, evidence displayed that rice intake could protect against risk of mortality from cardiovascular diseases (18). So, the association between carbohydrate intake from refined grains, such as white rice and CVD risk factors still remain uncertain (18). We need more information in this regard from different regions. Interpretation of results regarding the dietary factors is usually complicated because the diets are composed of many foods containing many nutrients. Increasing consumption of refined grain in Iran could be a cause for high prevalence of CVDs. Previous investigations from Iran have shown an inverse association between consumption of whole grain and metabolic syndrome (19) as well as hypertriglyceridemic waist (20). On the other hand, most of the previously-published studies have been done in western countries with different lifestyles, and scant data are available from the Middle East region, including Iran. White rice is a major source of carbohydrate and energy intake in Iranian diet (21), and few studies have specifically focused on white rice. Therefore, the present study investigates the association between white rice consumption and CVD risk factors among Iranian population.

\section{MATERIALS AND METHODS}

\section{Participants}

This was a cross-sectional study done in the structure of Isfahan Healthy Heart Program (IHHP). The IHHP was a comprehensive community-based programme for prevention and control of cardiovascular diseases and promotion of healthy lifestyle. This programme was started in 1999 and concluded after 7 years in 2006 (22). The IHHP was conducted by Isfahan Cardiovascular Research Center and Isfahan Provincial Health Office together. In total, 12,514 men and women older than 19 years were selected from three cities: Isfahan, Najafabad, and Arak. Sample selection was done by multistage random cluster-sampling method. Complete information on sampling process has been presented elsewhere $(22,23)$. This study has been done based on the available information from the initial phase of IHHP. Males with complete data on dietary and anthropometric information, plasma glucose, lipid profiles, and confounding variables were considered inclusion criteria, and history of chronic diseases and taking medication were considered exclusion criteria. As a result, 3,006 men were included in the present study. At arriving time to clinic, after full justification of the study protocol, each participant was asked to fill the consent form. The current study has received the consent of the Isfahan Cardiovascular Research Center Ethics Committee and other relevant organizations.

\section{Assessment of dietary intake}

Dietary intakes of study participants were assessed by skilled technicians, with a 49-item food frequency questionnaire. The validity of the questionnaire was confirmed by Medical Education Development Center (22). For each item, participants were asked about the portion-sizes and frequency of consumption in the previous year. Those food items were reported as daily, weekly and monthly consumption. For analysis, all of those food items were converted to daily consumption. Each serving of white rice comprised 5 table spoonful. We also assessed quality of diet by global dietary index (GDI). The GDI represents the average of the mean of 29 questions on intake frequency in seven categories. Smaller global dietary index represents better habits (24).

\section{Assessment of biological factors}

Participants were fasting for 12 hours before blood 
sampling. Collected samples were frozen at $-20{ }^{\circ} \mathrm{C}$ until analysis in 72 hours at the central laboratory of Isfahan Cardiovascular Research Center. Enzymatic colorimetric method was used in measuring total cholesterol and triglyceride levels. Determination of HDL cholesterol level was done after dextran sulphate-magnesium chloride sedimentation of non-HDL cholesterol. Calculation of LDL cholesterol was done by using the Friedewald equation (25). Diabetes, high FBS level, hypertention, hypertriglyceridemia, hyperlipidemia, hypercholesterolemia, high LDL level, and low HDL level were considered CVD risk factors. Having 3 or more of the following risk factors was described as metabolic syndrome: FBS $\geq 126 \mathrm{mg} / \mathrm{dL}$ or waist $>102 \mathrm{~cm}$ for men and $>88 \mathrm{~cm}$ for women or TG $\geq 150 \mathrm{mg} / \mathrm{dL}$ or $\mathrm{HDL}<40 \mathrm{mg} / \mathrm{dL}$ for men and $<50$ $\mathrm{mg} / \mathrm{dL}$ for women or systolic blood pressure $\geq 130$ $\mathrm{mmHg}$ and diastolic $\geq 85 \mathrm{mmHg}$. Diabetes mellitus was described as FBS $\geq 126 \mathrm{mg} / \mathrm{dL}$ or glucose $2 \mathrm{hpp}$ $\geq 200 \mathrm{mg} / \mathrm{dL}$ or using drug for diabetes. Hypercholesterolemia was described as cholesterol $\geq 240 \mathrm{mg} /$ $\mathrm{dL}$, high LDL level as LDL $\geq 160 \mathrm{mg} / \mathrm{dL}$, low HDL level as HDL >40 mg/dL for men and $>50 \mathrm{mg} / \mathrm{dL}$ for women, and hypertriglyceridemia was described as TG $\geq 200 \mathrm{mg} / \mathrm{dL}$. Having one disorder in the above lipid profiles was described as hyperlipidemia. High FBS level was described as FBS $\geq 126 \mathrm{mg} / \mathrm{dL}$ (26).

\section{Assessment of other variables}

In a face-to-face method, skilled interviewers collected socioeconomic and demographic data (on age, education, marriage, and income), medical history, information on smoking, physical activity (using Baecke questionnaire of habitual physical activity (27), and medication. Measurement of height was done with bare feet by a metal ruler, and measurement of weight was done by a calibrated scale in light clothing. Calculation of body mass index (BMI) was done as weight (kg) divided by height (m) squared. Measurement of waist-circumference was done at a level midway between the lower rib margin and iliac crest and hip-circumference at the greatest area.

\section{Statistical methods}

We used SPSS 15 software for all statistical analyses. Student's $t$-test was used for comparing means of continuous variables between categories of white rice intake. Chi-square test was applied to compare categorical variables. Logistic regression was used for exploring the associations between risk factors of cardiovascular diseases and category of white rice consumption in different models. First, we adjusted for socioeconomic and demographic variables, such as age, sex, education, marriage, income, smoking, and physical activity, and then a last adjustment was done for BMI. In both models, consumption of $\leq 7$ times per week was used as a reference.

\section{RESULTS}

Components of Iranian rice are provided in Table 1. The table has been taken from the table of Iranian food component (28). We reported different kinds of white rice which might be consumed by Iranian population.

Sociodemographic characteristics of the study participants, separately by frequency of white rice consumption, are shown in Table 2. Married people ate rice significantly less than single people. People who had higher education in terms of years of schooling consumed rice more than people with lower education. Based on our data, younger people have eaten significantly less than the elders. Eating white rice was not significantly different among those at different levels of income.

When we assessed risk factors of cardiovascular diseases among the study participants by frequency of white rice consumption per week (Table 3), we found no significant differences for glucose, lipid profiles, and inflammatory and CBC factors. We couldn't find any significant difference between BMI and waist-circumference among those at different categories of white rice intake.

Mean energy intake and global dietary index in two groups were not different (Table 4 ) in our study. We also couldn't see any difference for dairy, liquid oil, fruit, and vegetables in two groups but mean consumption of rice, grain, meat, sweet drink, and solid oil was significantly different, and people in 7-14 times intake group ate these items more than people in $<7$ times intake group.

Multivariate associations between risk factors of cardiovascular diseases and frequency of eating white rice are indicated in Table 5 . We failed to find any significant association between these risk factors and frequency of white rice consumption, neither in crude model nor in adjusted models. 


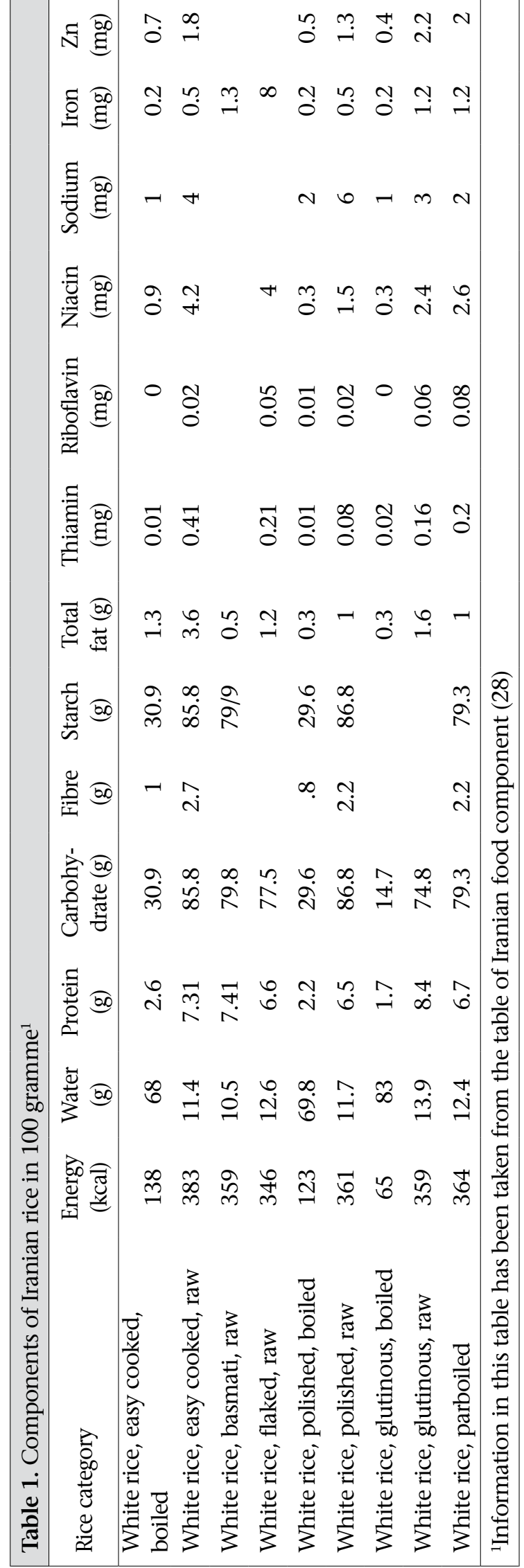

\section{DISCUSSION}

In this cross-sectional study on over 3,000 men, we failed to find any association between white rice consumption and risk factors of cardiovascular diseases. In Asian countries, like Iran, rice is a staple food. Higher consumption of white rice in these countries has been associated with higher risk of diabetes, metabolic syndrome, or CVDs $(13,17,29)$. Whole grains, like brown rice, are rich in fibre and some plant components that are responsible for their positive effect on cardiovascular and metabolic function. During the refining process, the biologically-active factors, bran, and germ are removed, and the carbohydrate-rich endosperm section is usually retained (30).

Refined grains are typically rich in energy and poor in nutrient content, which may increase the risk of chronic diseases (31). Findings on the association between refined grain consumption and risk of chronic diseases are inconsistent (32). Studies on the associations between refined grain intake and blood pressure or risk of CVDs are less reliable than those for whole grain intake $(33,34)$.

The results of the current study were in line with some previous studies that could not find positive association between white rice or refined grain consumption and CVD risk factors. In a study among Italians, rice intake was not associated with myocardial infarction (35). In another study on Indians, rice intake, in comparison with other sources of carbohydrate, had lower potential to increase postprandial glycaemia and TG levels (36). McKeown et al. reported no association between refined grain intake and metabolic risk factors (11). Other studies also had no evidence for effect of refined grain on heart disease (37-39), type 2 diabetes $(16,40)$, mortality due to CVDs (41), and risk of hypertension (42). Epidemiologic studies also reported that refined grain intake is not associated with risk of type 2 diabetes (40).

Conversely, in some studies, refined grain intake was positively associated with the higher risk of metabolic diseases (19). According to some reports, refined grain intake was associated with higher fasting glucose level (41), higher hyperinsulinemia (43), risk of type II diabetes $(16,44,45)$, stroke (46), and hypertriglyceridemia (20). Crosssectional studies have reported a direct association between refined grain intake and prevalence of metabolic syndrome $(19,41,47)$. White rice 


\begin{tabular}{|c|c|c|c|}
\hline \multirow{2}{*}{ Variable } & \multicolumn{2}{|c|}{ White rice intake } & \multirow{2}{*}{$\mathrm{p}$ value } \\
\hline & $<7$ times per week & 7-14 times per week & \\
\hline Physical activity (mets.h/day) & $1102.2 \pm 537.6$ & $1063.6 \pm 545.0$ & 0.40 \\
\hline Married (\%) & 79 & 72 & $<0.05$ \\
\hline \multicolumn{4}{|l|}{ Education (\%) } \\
\hline $0-<6$ years & 38 & 28 & $<0.05$ \\
\hline $6-12$ years & 48 & 53 & \\
\hline$>12$ years & 14 & 19 & \\
\hline Age (years) & $39.0 \pm 15.2$ & $34.5 \pm 13.2$ & $<0.001$ \\
\hline \multicolumn{4}{|l|}{ Age $(\%)$} \\
\hline $19-<25$ years & 92 & 8 & $<0.001$ \\
\hline $25-<35$ years & 93 & 7 & \\
\hline $35-<45$ years & 95 & 5 & \\
\hline $45-<55$ years & 96 & 4 & \\
\hline $55-65$ years & 96 & 4 & \\
\hline$>65$ years & 98 & 2 & \\
\hline \multicolumn{4}{|l|}{ Income (\%) } \\
\hline US\$ $<100$ per month & 94 & 6 & 0.22 \\
\hline US\$ $100-300$ per month & 93 & 7 & \\
\hline US $\$ \geq 300$ per month & 100 & 0 & \\
\hline
\end{tabular}

\begin{tabular}{|c|c|c|c|}
\hline & \multicolumn{2}{|c|}{ White rice intake } & \multirow{2}{*}{$\mathrm{p}$ value } \\
\hline & $<7$ times per week & 7-14 times per week & \\
\hline Fasting blood sugar (mg/dL) & $83.2 \pm 29.3$ & $82.0 \pm 21.1$ & 0.60 \\
\hline Glucose (2hpp) (mg/dL) & $97.6 \pm 50.6$ & $95.9 \pm 44.6$ & 0.66 \\
\hline Cholesterol (mg/dL) & $197.9 \pm 49.1$ & $197.7 \pm 52.7$ & 0.94 \\
\hline Triglycerides (mg/dL) & $188.3 \pm 126.6$ & $177.4 \pm 116.2$ & 0.28 \\
\hline $\mathrm{HDL}(\mathrm{mg} / \mathrm{dL})$ & $45.5 \pm 9.9$ & $45.4 \pm 10.0$ & 0.85 \\
\hline $\mathrm{LDL}(\mathrm{mg} / \mathrm{dL})$ & $116.2 \pm 40.0$ & $118.1 \pm 46.3$ & 0.57 \\
\hline Apolipoprotein A (mg/dL) & $142.6 \pm 31.2$ & $142.0 \pm 36.7$ & 0.67 \\
\hline Apolipoprotein B (mg/dL) & $113.2 \pm 31.7$ & $107.6 \pm 22.9$ & 0.34 \\
\hline CRP-quantitative (mg/dL) & $3.1 \pm 1.2$ & $3.0 \pm 1.0$ & 0.94 \\
\hline $\mathrm{RBC}(\mathrm{x} 106 / \mu \mathrm{L})$ & $5.3 \pm 0.5$ & $5.2 \pm 0.4$ & 0.35 \\
\hline Haemoglobin $(g / d L)$ & $15.2 \pm 1.3$ & $15.1 \pm 1.2$ & 0.38 \\
\hline Haematocrit (\%) & $45.6 \pm 3.5$ & $45.3 \pm 3.3$ & 0.30 \\
\hline Body mass index $\left(\mathrm{kg} / \mathrm{m}^{2}\right)$ & $24.8 \pm 4.3$ & $24.5 \pm 4.7$ & 0.30 \\
\hline Waist-circumference $(\mathrm{cm})$ & $90.6 \pm 89.5$ & $89.5 \pm 11.5$ & 0.24 \\
\hline Waist-to-hip ratio & $0.9 \pm 0.1$ & $0.9 \pm 0.1$ & 0.27 \\
\hline
\end{tabular}

intake was adversely associated with mortality from coronary heart disease (CHD), heart failure, and CVD risk in men $(18,48)$. Two cohort stud- ies also reported an inverse association between carbohydrate intake, mostly rice, and CHD risk factors among men $(49,50)$. 


\begin{tabular}{|c|c|c|c|}
\hline & \multicolumn{2}{|c|}{ White rice intake } & \multirow{2}{*}{$\mathrm{p}$ value } \\
\hline & $<7$ times per week & 7-14 times per week & \\
\hline Energy (kcal/day) & $1839.7 \pm 776.7$ & $2106.5 \pm 634.5$ & 0.19 \\
\hline Global dietary index & $1.1 \pm 0.3$ & $1.1 \pm 0.3$ & 0.20 \\
\hline Solid oil ${ }^{2}$ & $6.43 \pm 4.0$ & $7.8 \pm 5.0$ & $<0.001$ \\
\hline Liquid oil & $2.6 \pm 3.5$ & $2.8 \pm 3.7$ & 0.34 \\
\hline Grain & $2.8 \pm 2.0$ & $3.6 \pm 3.3$ & $<0.05$ \\
\hline Fruit & $6.2 \pm 3.5$ & $6.5 \pm 4.3$ & 0.29 \\
\hline Vegetables & $5.4 \pm 3.1$ & $5.8 \pm 4.2$ & 0.16 \\
\hline Meat & $5.8 \pm 3.0$ & $7.1 \pm 3.8$ & $<0.001$ \\
\hline Dairy product & $1.5 \pm 2.6$ & $1.7 \pm 3.0$ & 0.36 \\
\hline Sweet drink & $1.9 \pm 2.2$ & $2.6 \pm 3.0$ & $<0.05$ \\
\hline Rice and bread & $22.4 \pm 5.9$ & $30.5 \pm 6.1$ & $<0.001$ \\
\hline
\end{tabular}

As mentioned, results about the association of refined grains and risk factors of chronic diseases are contradictory (32). This difference might be explained by the diversity in glycaemic indices of different refined grains as the GI of different rice categories among the Vietnamese is from 86 to 109 but, based on the results of the systematic review, the mean GI for white rice was 64 and for brown rice was 55 (51). High-GI diet generates a high postprandial blood glucose level which produce a high insulin demand and metabolic risk for long time $(52,53)$. A high GI and also high amount of carbohydrate diet (GL) have been associated with higher risk of metabolic syndrome (47). In a cohort study on the Chinese, intake of food high in GI or GL, particularly rice, was positively associated with risk of type 2 diabetes (17). Foods containing refined grains are major suppliers of high-GL foods, and several studies revealed that GL is positively associated with lower glycaemic control or metabolic risk $(54,55)$.

Although nobody can deny the result of previous studies on the association between white rice intake and risk of metabolic syndrome and the beneficial effect of whole grain, we did not find any relationship between white rice and CVD risk factors. One possible reason for not finding positive association between white rice and CVD risk factors in our study could be the GI in Iranian rice as well as cooking method. Previous studies on Iranian rice determined some kinds of low-GI rice. Darabi et al. (56) reported that GI of rice Binam was $44 \pm 9$ and, in another study (57), GI of Sorna Pearl rice was reported to be $52.2 \pm 5.1$. They assumed that the low
GI of these kinds of rice could be because of different cooking methods and amylase content in Iranian rice (56). Although white rice, in comparison with brown rice, has no biologically-active agents, lower GI in Iranian rice could be a compensation factor that diminishes the negative effect of this refined grain.

\section{Limitations}

There are several limitations in our study that should be considered. First, our study had a crosssectional design. Thus, our findings do not allow us to make conclusion about the causality. Future prospective studies may give stronger documentation. On the other hand, we used FFQ for the dietary assessment as previous studies explained; FFQ would lead to under-estimation of refined grain intakes (58). The GI and GL of the white rice were not measured in the present study.

\section{Conclusions}

Grains as a main source of carbohydrate have important role in the diet of different populations, especially among the Asians. Moreover, importance of biologically-active and other components in whole grains is not deniable. There was no significant association between white rice intake and CVD risk factors among Iranian men. Further prospective studies with a semi-quantitative FFQ or dietary record questionnaire, representing type and portion-size of rice intake as well as cooking methods and other foods consumed with rice that affect GI of rice are required to support our finding and to illustrate the probable mechanism. 


\begin{tabular}{|c|c|c|c|}
\hline & \multicolumn{2}{|c|}{ White rice intake } & \multirow{2}{*}{$\mathrm{p}$ value } \\
\hline & $<7$ times per week & 7-14 times per week & \\
\hline \multicolumn{4}{|c|}{ Metabolic syndrome $^{3}$} \\
\hline Crude & 1.00 & $0.85(0.53-1.35)$ & 0.45 \\
\hline Model $1^{1}$ & 1.00 & $1.22(0.74-2.02)$ & 0.42 \\
\hline Model $2^{2}$ & 1.00 & $1.25(0.72-2.18)$ & 0.42 \\
\hline \multicolumn{4}{|c|}{ Diabetes Mellitus ${ }^{4}$} \\
\hline Crude & 1.00 & $0.68(0.32-1.48)$ & 0.33 \\
\hline Model 1 & 1.00 & $1.07(0.48-2.42)$ & 0.87 \\
\hline Model 2 & 1.00 & $1.06(0.47-2.43)$ & 0.88 \\
\hline \multicolumn{4}{|c|}{ Hypercholesterolemia $^{5}$} \\
\hline Crude & 1.00 & $1.12(0.76-1.66)$ & 0.56 \\
\hline Model 1 & 1.00 & $1.29(0.86-1.94)$ & 0.23 \\
\hline Model 2 & 1.00 & $1.19(0.77-1.84)$ & 0.44 \\
\hline \multicolumn{4}{|c|}{ High LDL level $^{6}$} \\
\hline Crude & 1.00 & $0.87(0.53-1.42)$ & 0.57 \\
\hline Model 1 & 1.00 & $1.03(0.61-1.73)$ & 0.91 \\
\hline Model 2 & 1.00 & $0.90(0.52-1.56)$ & 0.70 \\
\hline \multicolumn{4}{|c|}{ Low HDL level ${ }^{7}$} \\
\hline Crude & 1.00 & $1.17(0.84-1.63)$ & 0.35 \\
\hline Model 1 & 1.00 & $1.09(0.77-1.56)$ & 0.60 \\
\hline Model 2 & 1.00 & $1.10(0.78-1.57)$ & 0.58 \\
\hline \multicolumn{4}{|c|}{ Hypertriglyceridemia $^{8}$} \\
\hline Crude & 1.00 & $0.75(0.53-1.07)$ & 0.11 \\
\hline Model 1 & 1.00 & $0.80(0.56-1.16)$ & 0.24 \\
\hline Model 2 & 1.00 & $0.78(0.52-1.16)$ & 0.21 \\
\hline \multicolumn{4}{|c|}{ Hyperlipidemia $^{9}$} \\
\hline Crude & 1.00 & $0.96(0.70-1.30)$ & 0.78 \\
\hline Model 1 & 1.00 & $0.98(0.71-1.36)$ & 0.90 \\
\hline Model 2 & 1.00 & $0.96(0.68-1.34)$ & 0.79 \\
\hline \multicolumn{4}{|c|}{ High FBS level ${ }^{10}$} \\
\hline Crude & 1.00 & $0.56(0.20-1.53)$ & 0.26 \\
\hline Model 1 & 1.00 & $0.84(0.30-2.38)$ & 0.74 \\
\hline Model 2 & 1.00 & $0.85(0.30-2.44)$ & 0.77 \\
\hline \multicolumn{4}{|c|}{$\begin{array}{l}{ }^{1} \text { Model 1: Adjusted for sociodemographic variables; }{ }^{2} \text { Model } 2 \text { : Adjusted for sociodemographic variables } \\
\text { and BMI; }{ }^{3} \mathrm{Having} 3 \text { or more factors: FBS }>126 \mathrm{mg} / \mathrm{dL} \text { or waist-circumference }>102 \mathrm{~cm} \text { for men and }>85 \mathrm{~cm} \\
\text { for women or TG }>150 \mathrm{mg} / \mathrm{dL} \text { or } \mathrm{HLD}<40 \mathrm{mg} / \mathrm{dL} \text { for men and }<50 \mathrm{mg} / \mathrm{dL} \text { for women or systolic blood } \\
\text { pressure }>130 \mathrm{mmHg} \text { and diastolic }>85 \mathrm{mmHg} ; \mathrm{FBS}>126 \mathrm{mg} / \mathrm{dL} \text { or glucose } 2 \mathrm{hpp}>200 \mathrm{mg} / \mathrm{dL} \text { or using } \\
\text { of hypoglycaemic agents; }{ }^{5} \mathrm{Cholesterol}>240 \mathrm{mg} / \mathrm{dL} ;{ }^{6} \mathrm{LDL}>160 \mathrm{mg} / \mathrm{dL} ;{ }^{7} \mathrm{HDL}>40 \mathrm{mg} / \mathrm{dL} \text { for men and }>50 \\
\mathrm{mg} / \mathrm{dL} \text { for women; }{ }^{8} \mathrm{TG}>200 \mathrm{mg} / \mathrm{dL} ;{ }^{9} \text { Having one disorder in the above lipid profiles; }{ }^{10} \mathrm{FBS}>126 \mathrm{mg} / \mathrm{dL}\end{array}$} \\
\hline
\end{tabular}

\section{ACKNOWLEDGEMENTS}

The study used data from the programme conducted by Isfahan Cardiovascular Research Center (ICRC) - a WHO collaborating centre-in collabo- ration with Isfahan Provincial Health Office, both affiliated to Isfahan University of Medical Sciences (IUMS). The programme was supported by a grant (No. 31309304) of the Iranian Budget and Plan- 
ning Organization as well as the Deputy for Health of the Iranian Ministry of Health, Treatment and Medical Education, and the Iranian Heart Foundation (IHF). We are thankful to the collaborating teams in ICRC, Isfahan Provincial Health Office, Najafabad Health Office, and Arak University of Medical Sciences.

\section{REFERENCES}

1. Graham I, Atar D, Borch-Johnsen K, Boysen G, Burell G, Cifkova R et al.; European Society of Cardiology (ESC) Committee for Practice Guidelines (CPG). European guidelines on cardiovascular disease prevention in clinical practice: executive summary: Fourth Joint Task Force of the European Society of Cardiology and Other Societies on Cardiovascular Disease Prevention in Clinical Practice (Constituted by representatives of nine societies and by invited experts). Eur Heart J 2007;28:2375-414.

2. Allender S, Scarborough P, Peto V, Rayner M, Leal J, Luengo-Fernandez R et al. European cardiovascular disease statistics: 2008 edition. Brussels: European Heart Network, 2008. 112 p.

3. Sarraf-Zadegan N, Boshtam M, Rafiei M. Risk factors for coronary artery disease in Isfahan, Iran. Eur J Public Health 1999;9:20-6.

4. Sarraf-Zadegan N, Boshtam M, Malekafzali H, Bashardoost N, Sayed-Tabatabaei FA, Rafiei M et al. Secular trends in cardiovascular mortality in Iran, with special reference to Isfahan. Acta Cardiol 1999;54:327-33.

5. Azizi F, Rahmani M, Emami H, Mirmiran P, Hajipour $\mathrm{R}$, Madjid $\mathrm{M}$ et al. Cardiovascular risk factors in an Iranian urban population: Tehran lipid and glucose study (phase 1). Soz Praventivmed 2002;47:408-26.

6. Seeman T, Mendes de Leon C, Berkman L, Ostfeld A. Risk factors for coronary heart disease among older men and women: a prospective study of communitydwelling elderly. Am J Epidemiol 1993;138:1037-49.

7. Azadbakht L, Esmaillzadeh A. Dietary and non-dietary determinants of central adiposity among Tehrani women. Public Health Nutr 2008;11:528-34.

8. $\mathrm{Hu} \mathrm{FB}$, Willett WC. Optimal diets for prevention of coronary heart disease. JAMA 2002;288:2569-78.

9. Azadbakht L, Fard NRP, Karimi M, Baghaei MH, Surkan PJ, Rahimi M et al. Effects of the Dietary Approaches to Stop Hypertension (DASH) eating plan on cardiovascular risks among type 2 diabetic patients: a randomized crossover clinical trial. Diabetes Care 2011;34:55-7.

10. Azadbakht L, Surkan PJ, Esmaillzadeh A, Willett WC. The dietary approaches to stop hypertension eating plan affects C-reactive protein, coagulation abnor- malities, and hepatic function tests among type 2 diabetic patients. J Nutr 2011;141:1083-8.

11. McKeown NM, Meigs JB, Liu S, Wilson PWF, Jacques $\mathrm{PF}$. Whole-grain intake is favorably associated with metabolic risk factors for type 2 diabetes and cardiovascular disease in the Framingham Offspring Study. Am J Clin Nutr 2002;76:390-8.

12. Slavin JL, Martini MC, Jacobs DR, Jr., Marquart L. Plausible mechanisms for the protectiveness of whole grains. Am J Clin Nutr 1999;70(Suppl 3):459S-63S.

13. Radhika G, Van Dam RM, Sudha V, Ganesan A, Mohan V. Refined grain consumption and the metabolic syndrome in urban Asian Indians (Chennai Urban Rural Epidemiology Study 57). Metabolism 2009;58:675-81.

14. Slavin J. Why whole grains are protective: biological mechanisms. Proc Nutr Soc 2003;62:129-34.

15. Brand-Miller JC. Postprandial glycemia, glycemic index, and the prevention of type 2 diabetes. Am J Clin Nutr 2004;80:243-4.

16. Liu S, Willett WC, Stampfer MJ, Hu FB, Franz M, Sampson L et al. A prospective study of dietary glycemic load, carbohydrate intake, and risk of coronary heart disease in US women. Am J Clin Nutr 2000;71:1455-61.

17. Villegas R, Liu S, Gao Y-T, Yang G, Li H, Zheng W et al. Prospective study of dietary carbohydrates, glycemic index, glycemic load, and incidence of type 2 diabetes mellitus in middle-aged Chinese women. Arch Intern Med 2007;167:2310-6.

18. Eshak ES, Iso H, Date C, Yamagishi K, Kikuchi S, Watanabe $\mathrm{Y}$ et al. Rice intake is associated with reduced risk of mortality from cardiovascular disease in Japanese men but not women. J Nutr 2011;141:595602.

19. Esmaillzadeh A, Mirmiran P, Azizi F. Whole-grain consumption and the metabolic syndrome: a favorable association in Tehranian adults. Eur J Clin Nutr 2005;59:353-62.

20. Esmaillzadeh A, Mirmiran P, Azizi F. Whole-grain intake and the prevalence of hypertriglyceridemic waist phenotype in Tehranian adults. Am J Clin Nutr 2005;81:55-63.

21. Kimiagar SM, Ghaffarpour M, Houshiar-Rad A, Hormozdyari H, Zellipour L. Food consumption pattern in the Islamic Republic of Iran and its relation to coronary heart disease. East Mediterr Health J 1998;4:53947.

22. Sarraf-Zadegan N, Sadri G, Malek Afzali H, Baghaei M, Mohammadi Fard N, Shahrokhi S et al. Isfahan Healthy Heart Programme: a comprehensive integrated community-based programme for cardiovascular 
disease prevention and control. Design, methods and initial experience. Acta Cardiol 2003;58:309-20.

23. Sarrafzadegan N, Baghaei A, Sadri G, Kelishadi R, Malekafzali $\mathrm{H}$, Boshtam $\mathrm{M}$ et al. Isfahan healthy heart program: evaluation of comprehensive, communitybased interventions for non-communicable disease prevention. Preven Control 2006;2:73-84.

24. Mohammadifard N, Sarrafzadegan N, Nouri F, Sajjadi $\mathrm{F}$, Alikhasi $\mathrm{H}$, Maghroun $\mathrm{M}$ et al. Using factor analysis to identify dietary patterns in Iranian adults: Isfahan Healthy Heart Program. Int J Public Health 2012;57:235-41.

25. Friedewald WT, Levy RI, Fredrickson DS. Estimation of the concentration of low-density lipoprotein cholesterol in plasma, without use of the preparative ultracentrifuge. Clin Chem 1972;18:499-502.

26. National Cholesterol Education Program (NCEP) Expert Panel on Detection, Evaluation, and Treatment of High Blood Cholesterol in Adults (Adult Treatment Panel III). Third report of the National Cholesterol Education Program (NCEP) expert panel on detection, evaluation, and treatment of high blood cholesterol in adults (Adult Treatment Panel III): final report. Circulation 2002;106:3143-421.

27. Pereira MA, FitzerGerald SJ, Gregg EW, Joswiak ML, Ryan WJ, Suminski RR et al. A collection of physical activity questionnaires for health-related research. Med Sci Sports Exerc 1997;29(Suppl 6):S1-205.

28. Dorosti Motlagh AR, Tabatabaei M. Table of Iranian food component. 1st ed. Tehran: Iran Donyaye Taghzieh Press, 2007:5-22.

29. Murakami K, Sasaki S, Takahashi Y, Okubo H, Hosoi Y, Horiguchi $\mathrm{H}$ et al. Dietary glycemic index and load in relation to metabolic risk factors in Japanese female farmers with traditional dietary habits. Am J Clin Nutr 2006;83:1161-9.

30. Liu S. Intake of refined carbohydrates and whole grain foods in relation to risk of type 2 diabetes mellitus and coronary heart disease. J Am Coll Nutr 2002;21:298-306.

31. Steffen LM, Jacobs DR, Jr., Stevens J, Shahar E, Carithers T, Folsom AR. Associations of whole-grain, refined-grain, and fruit and vegetable consumption with risks of all-cause mortality and incident coronary artery disease and ischemic stroke: the Atherosclerosis Risk in Communities (ARIC) Study. Am J Clin Nutr 2003;78:383-90.

32. Newby PK, Maras J, Bakun P, Muller D, Ferrucci L, Tucker KL. Intake of whole grains, refined grains, and cereal fiber measured with 7-d diet records and associations with risk factors for chronic disease. Am J Clin Nutr 2007;86:1745-53.
33. Ascherio A, Hennekens C, Willett WC, Sacks F, Rosner B, Manson J et al. Prospective study of nutritional factors, blood pressure, and hypertension among US women. Hypertension 1996;27:1065-72.

34. Steffen LM, Kroenke CH, Yu X, Pereira MA, Slattery ML, Van Horn L et al. Associations of plant food, dairy product, and meat intakes with 15-y incidence of elevated blood pressure in young black and white adults: the Coronary Artery Risk Development in Young Adults (CARDIA) Study. Am J Clin Nutr 2005;82:1169-77.

35. Tavani A, Bosetti C, Negri E, Augustin LS, Jenkins DJA, La Vecchia C. Carbohydrates, dietary glycaemic load and glycaemic index, and risk of acute myocardial infarction. Heart 2003;89:722-6.

36. Ezenwaka CE, Kalloo R. Carbohydrate-induced hypertriglyceridaemia among West Indian diabetic and non-diabetic subjects after ingestion of three local carbohydrate foods. Indian J Med Res 2005;121:23-31.

37. Jacobs DR, Jr., Meyer KA, Kushi LH, Folsom AR. Wholegrain intake may reduce the risk of ischemic heart disease death in postmenopausal women: the Iowa Women's Health Study. Am J Clin Nutr 1998;68:248-57.

38. Jacobs DR, Jr., Meyer KA, Kushi LH, Folsom AR. Is whole grain intake associated with reduced total and causespecific death rates in older women? The Iowa Women's Health Study. Am J Public Health 1999;89:322-9.

39. Liu S, Sesso HD, Manson JE, Willett WC, Buring JE. Is intake of breakfast cereals related to total and cause-specific mortality in men? Am J Clin Nutr 2003;77:594-9.

40. Meyer KA, Kushi LH, Jacobs DR, Jr., Slavin J, Sellers TA, Folsom AR. Carbohydrates, dietary fiber, and incident type 2 diabetes in older women. Am J Clin Nutr 2000;71:921-30.

41. Sahyoun NR, Jacques PF, Zhang XL, Juan W, McKeown NM. Whole-grain intake is inversely associated with the metabolic syndrome and mortality in older adults. Am J Clin Nutr 2006;83:124-31.

42. Wang L, Gaziano JM, Liu S, Manson JE, Buring JE, Sesso HD. Whole- and refined-grain intakes and the risk of hypertension in women. Am J Clin Nutr 2007;86:472-9.

43. Wirfält E, Hedblad B, Gullberg B, Mattisson I, Andrén C, Rosander U et al. Food patterns and components of the metabolic syndrome in men and women: a cross-sectional study within the Malmö Diet and Cancer cohort. Am J Epidemiol 2001;154:1150-9.

44. Nanri A, Mizoue T, Noda M, Takahashi Y, Kato M, Inoue $\mathrm{M}$ et al. Rice intake and type 2 diabetes in Japanese men and women: the Japan Public Health Center-based Prospective Study. Am J Clin Nutr 2010;92:1468-77. 
45. Zhang G, Malik VS, Pan A, Kumar S, Holmes MD, Spiegelman D et al. Substituting brown rice for white rice to lower diabetes risk: a focus-group study in Chinese adults. J Am Diet Assoc 2010;110:1216-21.

46. Liang W, Lee AH, Binns CW. White rice-based food consumption and ischemic stroke risk: a case-control study in southern China. J Stroke Cerebrovasc Dis 2010;19:480-4.

47. McKeown NM, Meigs JB, Liu S, Saltzman E, Wilson PWF, Jacques PF. Carbohydrate nutrition, insulin resistance, and the prevalence of the metabolic syndrome in the Framingham Offspring Cohort. Diabetes Care 2004;27:538-46.

48. Liu S, Manson JE, Stampfer MJ, Holmes MD, Hu FB, Hankinson SE et al. Dietary glycemic load assessed by food-frequency questionnaire in relation to plasma high-density-lipoprotein cholesterol and fasting plasma triacylglycerols in postmenopausal women. Am J Clin Nutr 2001;73:560-6.

49. McGee DL, Reed DM, Yano K, Kagan A, Tillotson J. Ten-year incidence of coronary heart disease in the Honolulu Heart Program. Relationship to nutrient intake. Am J Epidemiol 1984;119:667-76.

50. Garcia-Palmieri MR, Sorlie P, Tillotson J, Costas R, Jr., Cordero E, Rodriguez M. Relationship of dietary intake to subsequent coronary heart disease incidence: The Puerto Rico Heart Health Program. Am J Clin Nutr 1980;33:1818-27.
51. Atkinson FS, Foster-Powell K, Brand-Miller JC. International tables of glycemic index and glycemic load values: 2008. Diabetes Care 2008;31:2281-3.

52. Jenkins DJA, Wolever TMS, Taylor RH, Barker H, Fielden $\mathrm{H}$, Baldwin JM et al. Glycemic index of foods: a physiological basis for carbohydrate exchange. Am J Clin Nutr 1981;34:362-6.

53. Foster-Powell K, Holt SHA, Brand-Miller JC. International table of glycemic index and glycemic load values: 2002. Am J Clin Nutr 2002;76:5-56.

54. Liu S, Willett WC. Dietary glycemic load and atherothrombotic risk. Curr Atheroscler Rep 2002;4:454-61.

55. Willett W, Manson J, Liu S. Glycemic index, glycemic load, and risk of type 2 diabetes. Am J Clin Nutr 2002;76(Suppl):274S-80S.

56. Darabi A, Taleban FA, Esmaili M, Valaii N. Glycemic index of split peas, rice (Binam), kidney beans, green peas, "Lavash" bread and broad bean kernels in NIDDM subjects. Acta Med Iran 2000;38:79-83.

57. Zarrati M, Pirali M, Mirmiran P, Noori N, Nakhoda K, Najafi $\mathrm{H}$ et al. Glycemic index of various brands of rice in healthy individuals. Int J Endocrinol Metab 2008;6;200-4.

58. Hu FB, Rimm E, Smith-Warner SA, Feskanich D, Stampfer MJ, Ascherio A et al. Reproducibility and validity of dietary patterns assessed with a food-frequency questionnaire. Am J Clin Nutr 1999;69:243-9. 